\title{
Visual Reproduction I Subtest (WMS-IV)
}

National Cancer Institute

\section{Source}

National Cancer Institute. Visual Reproduction I Subtest (WMS-IV). NCI Thesaurus. Code C120348.

A subtest of the Wechsler Memory Scale, 4th Edition that assesses memory for nonverbal visual stimuli. A series of five designs is shown, one at a time, for 10 seconds each. After each design is presented, the subject is asked to draw the design from memory. 